\title{
The Impact of Direct Challenges to Student Endorsement of Teleological Reasoning on Understanding and Acceptance of Natural Selection
}

Jason Wingert ( $\sim$ jwingert@unca.edu )

University of North Carolina at Asheville

Gennie Bassett

University of North Carolina at Asheville

Caitlin Terry

University of North Carolina at Asheville

Jimin Lee

University of North Carolina at Asheville

\section{Research Article}

Keywords: teleology, evolution pedagogy, natural selection

Posted Date: January 6th, 2022

DOI: https://doi.org/10.21203/rs.3.rs-1226177/v1

License: (a) (i) This work is licensed under a Creative Commons Attribution 4.0 International License.

Read Full License 


\section{Abstract}

Background: Teleological reasoning is a cognitive bias purported to disrupt student ability to understand natural selection. Few studies have described pedagogical efforts to decrease student endorsement of teleological reasoning and measure the effects of this attenuation on the understanding and acceptance of evolution. This study examined the influence of explicit instructional activities directly challenging student endorsement of teleological explanations for evolutionary adaptations on their learning of natural selection over a semester-long undergraduate course in evolutionary medicine. In a convergent mixed-methods design this study combined pre- and post-semester survey data $(\mathrm{N}=83)$ on understanding natural selection, student endorsement of teleological reasoning, and acceptance of evolution, with thematic analysis of student reflective writing on their understanding and acceptance of natural selection and teleological reasoning.

Results: Student endorsement of teleological reasoning decreased and understanding and acceptance of natural selection increased during a course on human evolution with teleological intervention ( $\mathrm{f} 0.0001)$, compared to a control course. Endorsement of teleological reasoning was predictive of understanding of natural selection prior to the semester. Thematic analysis revealed that students were largely unaware of the concept of teleological reasoning prior to the course, but perceived attenuation of their own teleological reasoning by the end of the semester.

Conclusions: Students are unaware of their high levels of endorsement of teleological reasoning upon entrance into the undergraduate human evolution course, which is consequential because teleological reasoning is a predicter of natural selection understanding. We developed class activities to directly challenge student endorsement of unwarranted design teleological reasoning. As a result, students had decreased unwarranted teleological reasoning and increased acceptance and understanding of natural selection over the course of the semester. The data presented show that students are receptive to explicit instructional challenges to their teleological reasoning and that attenuation of this bias is associated with gains in natural selection understanding and acceptance.

\section{Introduction}

Evolution by natural selection is the fundamental unifying and organizational theory of biology, but student understanding of this topic is tenuous and challenged by multiple factors, including religiosity, parental attitudes toward evolution, student acceptance of evolution, and cognitive obstacles, such as teleological reasoning $(1-4)$. Teleological reasoning is the cognitive tendency to explain natural phenomena by their putative function, purpose, or end goals, according to some prescribed direction or plan, rather than by the natural forces that bring them about $(5,6)$. Design-based teleological reasoning is in opposition to the theory of evolution by natural selection because it suggests the common misunderstanding of natural selection as a forward-looking, rather than a blind, process $(7,8)$. Design teleology purports that an adaptation occurred according to the intentions of an external agent (external design teleology) or to fulfil the needs of the organism (internal design teleology)(8). This can lead 
students to assume that all traits are adaptations that evolved toward a prescribed functional endpoint due to a sense of goal-directed agency or conscious intention $(9,10)$. Therefore, when students endorse design teleology they do not acknowledge the veridical evolutionary mechanisms of genetic variation from random genetic changes and sexual recombination or the importance of non-adaptive mechanisms such as genetic drift and gene flow. Several studies have shown that understanding evolution is disrupted by teleological reasoning $(4,11-14)$ and yet, science educators may underestimate the prevalence of the design teleological bias and its cognitive impacts (9). To suppress or regulate the design teleological bias with veridical views on the natural world is cognitively challenging, but necessary to accurately understand evolution $(1,8,15)$ and other biological sciences $(16)$.

A growing literature shows that teleological reasoning is universal, especially in children, and therefore, part of typical cognitive development. As early as preschool, children develop an intuitive preference for teleological explanations over physical-causal explanations across multiple domains, including humanmade artifacts and living and non-living things in nature (17-19). Kelemen and colleagues have differentiated between the warranted use of teleological explanations to describe the origins of humanmade artifacts and the unwarranted extension of teleology beyond human-made artifacts to also describe living and nonliving things in nature $(17,18,20)$. Teleological reasoning persists in high school $(13,21-25)$, college (26-28), and graduate school (29). College-educated adults demonstrate a tendency toward teleological reasoning when they are uncertain or lack knowledge of an appropriate explanation and when they are under timed test conditions $(26,30)$. Even academically active physical scientists, who normally subscribe to physical-causal explanations consistent with their extensive scientific training, default to teleological explanations when their cognitive resources are challenged by a timed or dual task (7). Therefore, the picture emerging from this body of research indicates that teleological reasoning is universal (31), but the strength of this bias can possibly be moderated after childhood by cultural factors, including education. Yet, extensive scientific education does not appear to completely revise and replace the bias $(7,14,32)$.

Given the universality and disruptiveness to biological learning of teleological reasoning, there is an emerging literature on how to address teleology in the classroom. González Galli et al (15) have proposed that a goal of biological education is to help students regulate their teleological reasoning when thinking about evolution. According to González Galli et al (15), in order to regulate teleological reasoning, the student must exhibit metacognitive vigilance that requires developing the following competencies: (i) knowledge of teleology, (ii) awareness of how teleology can be expressed both appropriately and inappropriately, and (ii) deliberate regulation of its use by the student (15). Kampourakis (8) suggests showing students that design teleology is problematic by explicitly addressing design teleology in the classroom and contrasting it with natural selection to evoke a conceptual tension between the two. However, while several authors have suggested that addressing teleological misconceptions should be explicitly incorporated into evolution courses $(4,22,33-38)$, we are aware of few empirical investigations on the effects of classroom efforts to systemically and explicitly address teleological reasoning in college students $(14,25,27,28)$. Jensen and Finley $(28)$ showed decreased student use of teleological explanations in an undergraduate introductory biology course that specifically included instruction on 
historical perspectives on teleology (i.e., Cuvier and Paley) and Lamarckian views on evolution. Similarly, author (14) provided evidence that instructional challenges to undergraduate student endorsement of teleological reasoning instruction significantly improves student understanding of fundamental concepts of evolution, decreases pervasive student misconceptions about evolution, and increases student acceptance of human evolution.

The purpose of the current study was to determine if education intended to directly challenge design teleology in the context of a human evolution course (conceived according to the framework of González Galli et al (15)) reduces student endorsement of teleological reasoning and impacts understanding natural selection compared to a control course. We sought to build on the existing literature by assessing endorsement of teleological reasoning, acceptance of evolution, and understanding of natural selection with previously established measures in undergraduates before and after taking a course on evolution. The survey of student endorsement of unwarranted teleological reasoning used in the current study was a sample selected from Keleman et al's (7) study of physical scientists' acceptance of teleological explanations in nature. We assessed student acceptance of evolution with the validated Inventory of Student Evolution Acceptance (39) and we measured understanding of natural selection with the Conceptual Inventory of Natural Selection (40). Since natural selection understanding is a multifactorial issue (1-4), we also measured student religiosity, parental attitudes, and prior evolution education. Additionally, we combined qualitative analysis of student responses to open-ended questions about their experiences exploring their tendencies to endorse teleological reasoning. The qualitative component allowed insights into the thought processes and difficulties students may have experienced when confronted with challenges to their teleological reasoning, but which may not have been observable on the surveys alone. Therefore, in a convergent mixed methods research design, we sought to address the following research questions: (RQ1) Does student teleological reasoning change over the course of a semester in response to explicit instruction on teleological reasoning? (RQ2) Do changes in teleological reasoning, or other factors, impact student understanding and acceptance of evolution? and (RQ3) What are students' metacognitive perceptions of their teleological reasoning in an evolution course?

\section{Methods}

\section{Participants}

Participants were undergraduate students $(\mathrm{N}=83)$ at a public liberal arts college in the Southeastern United States. Fifty-one students (mean age $(S D)=23.4(7.1)$ years, $64.7 \%$ female) were in a course on the evolutionary principles of human health and disease during three consecutive Fall semesters. The professor of the course had $>12$ years of teaching experience. The control group was comprised of thirtytwo students (mean age (SD) = 21.5 (6.3) years, 71.9\% female) enrolled in a Human Physiology course taught by the same professor. This study was deemed exempt from further review by the Institutional Review Board at UNC Asheville and all participants provided signed informed consent before participating in the study. 


\section{Course Description}

The evolutionary principles of health and disease course taught the fundamental principles of evolution in a mostly human context, with a specific focus on adaptation and maladaptation related to human health and disease. By considering human health from an evolutionary perspective, students gained insights into how the human body has adapted to its various environments, and why particular diseases occur in the modern world. This course explored the fundamentals of evolution, its relationship to the development of the human body over time, teleological thinking, pathophysiology attributable to evolution, and environmental and social evolutionary mismatches in the modern world which contribute to disease. This course consisted of lectures, group discussions on readings, weekly quizzes, and a final research project exploring the evolutionary principles of a chosen disease.

The activities to address teleological reasoning in the course included: (1) lectures related to core concepts in evolutionary biology. In lectures, students were given a definition and several examples of teleological reasoning compared with veridical evolutionary explanations. The class discussed how teleological reasoning is often used in biological explanations and how design teleology can disrupt learning of evolution. (2) Students completed three consecutive weekly quizzes asking them to identify the design teleological statement(s) from a list of multiple statements on evolutionary mechanisms and to correct the teleological statements with veridical evolutionary mechanisms. The correct answers to these quiz questions were discussed with students after grading. (3) There were weekly class discussions on assigned readings, which included explicit discussions on the distinctions between design teleological reasoning and more veridical scientific explanations. Students were encouraged to identify design teleological statements made by the author of the readings, professor, or other students during class discussions. (4) Finally, a short writing assignment in the tenth week of the semester asked students to respond to four open-ended questions (see Assessment below) on their level of teleological reasoning, how learning about teleology affected their learning of evolutionary concepts, and how awareness of teleology fits in the context of their understanding of the broader world. The class then discussed these reflections.

The Human Physiology (control) course neither specifically taught evolutionary principles nor addressed student teleological reasoning at any point, but did include frequent evolutionary explanations in response to student questions when appropriate.

\section{Study design and assessments}

This study used a convergent mixed methods design (41), where all participants completed both the quantitative and the qualitative strands. In the quantitative strand, students were asked to complete three surveys during the first, and again during the last, week of the semester. The first survey measured students' understanding of natural selection with the Conceptual Inventory of Natural Selection (CINS), which consists of 20 multiple-choice questions each with one correct answer (40). The validity and reliability of the CINS have been reported $(40,42)$. The CINS includes six questions (items $4,6,8,13,19$, 20) that either have teleological themes or teleological distractors as multiple-choice options, and 
therefore test teleological endorsements. These six questions were removed from all analyses of understanding of natural selection and analyzed separately as a secondary measure of teleological reasoning.

The second survey was a 36-item survey of teleological reasoning adapted from the larger measure created by Kelemen et al (7), which included 100 one-sentence explanations for "why things happen," presented as timed forced-choice statements to which participants responded as "true" or "false". Kelemen et al (7) used 30 test sentences describing scientifically unwarranted design teleological (i.e., inaccurate) explanations for various natural phenomena and 70 control sentences. The control sentences in the Kelemen et al (7) study included: 20 true causal explanations, 10 true teleological explanations, 30 false causal explanations, and 10 false teleological explanations. The Kelemen et al (7) measure was adapted in the current study to include 20 test sentences and 16 control sentences (4 true causal explanations, 5 true teleological explanations, 4 false causal explanations, and 3 false teleological explanations), chosen at random from each statement type (see Additional file 1). Only student responses to the twenty unwarranted teleological test statements were included in the analysis. An additional adaptation of the original measure is the use of a 5-point Likert scale in the current study to determine the student's level of agreement, rather than the previously used timed forced-choice test (7).

The third measure included the 24-item Inventory of Student Evolution Acceptance (I-SEA) which has been shown to be a reliable measure of evolution acceptance in college students $(39,43)$. Students completed the full I-SEA and responses to both the full I-SEA and the human evolution subsection were included in this analysis. The third survey also included student demographic information, level of prior exposure to evolution, number of previous courses on evolution in high school and college, level of religiosity, specific religious affiliation, and parent attitude toward evolution. The following survey questions used a 5-point Likert scale ranging from strongly disagree (1) to strongly agree (5) for student responses. Student prior educational exposure was measured by asking students the extent to which they agreed with the statement, "In previous courses, I have learned a lot about evolution." Students' perceptions of their parents' attitudes about evolution were asked separately for each parent (or guardian), with the question, "What attitude do you think your mother/father (or guardian) has toward evolution?" Students were asked how important religion was in their life, using a 4-point Likert-type scale, ranging from not important to very important.

In the qualitative strand, students were asked to complete written responses to the following four openended questions during the tenth week of the semester: 1) Please describe your level of acceptance of evolution. 2) Have your views on evolution changed since an earlier point in your life? If so, what has caused this change? If not, please describe your reasons. 3) Have the readings and discussions in class been consistent with your views about life or has it been challenging? Please explain your answer. 4) Please describe your thinking about the causes of nature, evolution, and human life. Has your use of teleology changed over the semester? 
Spearman correlations examined the relationships between measures. Wilcoxon signed-rank tests examined paired within-group differences between pre-and post-semester. Mann-Whitney U testse examined between group differences. Values are presented as mean (SD) and effect sizes are presented as Hedges' g. Internal consistency of the survey items was measured with Cronbach's alpha and criterion validity of the teleology measure was preliminarily assessed by Spearman correlation with the responses to the six teleology-themed questions on the CINS. Finally, we ran three independent multiple regressions using measured variables as predictors of the dependent variable in each regression to determine the relative influence of each variable on students' acceptance of evolution and their understanding of natural selection at pre-and post-semester. GraphPad Prism Version 9.3.0 (San Diego, CA) was used for all statistical analyses, except for Cronbach's alpha (calculated with Microsoft Excel version 16.16.27) and the multiple regression analyses (calculated with R; R Foundation for Statistical Computing, Vienna, Austria). Statistical significance was set at $p<0.05$.

\section{Qualitative analysis}

Two reviewers independently scored the responses to the open-ended questions for their level of evolution acceptance using a 5-point Likert scale ranging from strongly disagree to strongly agree. Interrater reliability was calculated for these ratings. Next, a thematic analysis was conducted on the student responses to the open-ended questions. The first step of the thematic analysis was for both reviewers to independently read each student response and identify themes (see Additional file 2). Only the themes related to student teleological reasoning and learning/acceptance of evolution were included in this analysis. The reviewers then independently re-read the student responses and identified when the themes were mentioned. After interrater reliability was established, only counts from one rater (JW) were used in the analysis. If a student mentioned the theme at least once in their responses to any of the openended questions, a score of " 1 " was recorded for that theme in the student's response. The total number of mentions was summed across students for each theme.

\section{Results}

Forty-eight of the 51 students in the evolutionary principles of health course completed all surveys at both pre- and post-semester ( $94 \%$ response rate). Of the three students not completing the surveys, two students did not complete the surveys at pre-semester and the other left college before the end of the semester. In the control course, three students' responses were eliminated because these students reported that they were simultaneously enrolled in a course on evolution. Three additional students did not complete the pre- or post-surveys for unspecified reasons. Therefore, the control group was comprised of 26 students that completed all surveys at pre- and post-semester ( $90 \%$ response rate).

The following analyses included data from the evolutionary principles of health course only, henceforth referred to as teleology intervention (TI). Four percent (4\%) of the students were sophomores, $36 \%$ juniors, $56 \%$ seniors, and $4 \%$ post-baccalaureate students. Prior to this course, students reported taking a mean $(S D)=0.43(0.64)$ courses on evolution in high school and a mean (SD) $=1.25(0.79)$ courses in college 
On 5-point Likert scales students self-scored their prior educational exposure on evolution as a mean (SD) $=3.27$ (1.25) and scored their parents' attitudes toward evolution as a mean (SD) = 3.38 (1.23). Selfreported religious affiliation included: 10\% Catholic, 0\% Eastern Religion, 14\% Fundamental Christian, 4\% Jewish, 0\% Muslim, 24\% None, 16\% Other Protestant, and 32\% reported Other. On the importance of religion in the students' lives, 38\% listed "not important," 20\% "slightly important," 16\% "moderately important," and 26\% listed "very important."

\section{Pre-semester data}

At pre-semester, students in the TI course with lower levels of teleological reasoning had higher understanding of natural selection (i.e., higher CINS scores) $(r=-0.65 ; p<0.0001)$ (Table 1). Students with lower levels of teleological reasoning had higher acceptance of evolution $(r=-0.44 ; p=0.0017)$ and lower religiosity $(r=0.35 ; p=0.014)$. Students reporting that their parents had more positive attitudes toward evolution had higher acceptance of evolution ( $r=0.58 ; p<0.0001)$. There were no differences between the $\mathrm{TI}$ course and the control course on any measure at pre-semester (see Additional file 3 ).

To control for all other variables and illustrate the relative influence of each variable (parental attitude, religiosity, prior education, teleological reasoning, and natural selection understanding) on students' incoming acceptance of evolution (I-SEA), we conducted a multiple linear regression (Table 3 ): $\mathrm{R}^{2}=.45$; $F(5,42)=6.88, p<0.0001$ (Adjusted $R^{2}=0.38$ ). Together, these variables accounted for $38 \%$ of the variance in student acceptance of evolution scores, with significant unique variance contributed only by parent attitude toward evolution (positively).

Multiple linear regression determined the relative influence of each variable on student understanding of natural selection (CINS without the six teleology questions) prior to instruction (Table 4): $R^{2}=.42 ; F(5,42$ ) $=6.02, p<0.00028$ (Adjusted $R^{2}=.35$ ). Together, these variables accounted for $35 \%$ of the variance with significant unique variance contributed by incoming teleological reasoning (negatively). To summarize, parental attitudes toward evolution were the greatest predictor of students' acceptance of evolution and teleological reasoning was the main predictor of natural selection understanding, prior to instruction.

\section{Pre-post comparisons}

Wilcoxon signed rank tests examined whether variables changed in response to the course material (Figure 1). Students improved their understanding of evolution (CINS without the six teleology questions) $\left(M_{\text {Pre }}=9.00\right.$ (2.92); $M_{\text {Post }}=10.27$ (2.35); Hedges' $\left.g=0.48 ; P=0.0001\right)$. CINS score increased in 64.5\%, stayed the same in $12.5 \%$, and decreased in $23.0 \%$ of students at post-semester compared to pre-semester. Students' endorsement of teleological reasoning decreased over the course of the semester $\left(M_{\text {Pre }}=3.00\right.$ (0.80); $M_{\text {Post }}=2.00$ (0.87); Hedges' g=1.20; $\left.P<0.0001\right)$. Student endorsement of teleological reasoning decreased in $96 \%$ of students and increased in two students. The decrease in endorsement of teleological reasoning is consistent with a significant improvement on the six CINS questions which had teleological themes or distractors $\left(M_{\text {Pre }}=2.15\right.$ (1.83); $M_{\text {Post }}=3.54$ (1.81); Hedges' $\left.g=0.76 ; P<0.0001\right)$. Student 
acceptance of evolution (I-SEA) increased ( $\mathrm{M}_{\text {Pre }}=100.50$ (15.55); $\mathrm{M}_{\text {Post }}=106.70$ (13.75); Hedges' $\mathrm{g}=0.42$; $\mathrm{P}<0.0001)$. Acceptance of evolution increased in $70.8 \%$, stayed the same in $14.6 \%$, and decreased in $14.6 \%$, of our sample. Similarly, student acceptance of human evolution (I-SEA $\left.A_{H E}\right)$ increased $\left(M_{P r e}=32.65\right.$ (6.63); $M_{\text {Post }}=35.40$ (5.38); Hedges' $g=0.46 ; P<0.0001$ ). Student level of religiosity did not change during the semester. No significant changes were observed on any of these measures in the control group (Additional file 3).

\section{Post-semester data}

Natural selection understanding at post-semester was significantly correlated with post-semester measures of teleological reasoning $(r=-0.38 ; p=0.0074)$, student religiosity $(r=-0.39 ; p=0.0064)$, and acceptance of evolution $(r=0.39 ; p=0.0068)$. Higher student religiosity was associated with lower levels of understanding of natural selection $(r=-0.38 ; p=0.0064)$ and lower levels of human evolution acceptance $(r=-0.53 ; p<0.0001)$. Students with lower levels of teleological reasoning had higher acceptance of evolution $(r=-0.44 ; p=0.0017)$.

We conducted a multiple linear regression to determine the relative influence of each variable, independently of the others, on the post-semester natural selection understanding (CINS) score. Overall, $45 \%$ of the variance was explained (Table 5): $R^{2}=.52 ; F(6,41)=7.40, p<0.0001$ (Adjusted $R^{2}=0.45$ ). Only pre-semester natural selection understanding $(p<0.001)$ contributed significant unique variance.

\section{Reliability and criterion validity of measures}

As a measure of internal consistency for the CINS, Cronbach's alpha was 0.81 at pre- and 0.77 at postsemester. For the teleology survey used in this study, Cronbach's alpha was 0.91 at pre- and 0.89 at postsemester. For the I-SEA, Cronbach's alpha was 0.95 at pre- and 0.96 at post-semester. The scores from the 36-item teleology measure based on Kelemen et al (7) significantly correlated with incorrect responses from the six teleology-themed questions on the CINS at pre- $(r=0.48 ; p=0.0006)$; and post- $(r=0.53$; $p=0.0001$ ) semester.

\section{Qualitative analysis}

Two raters independently scored each student response to the four open-ended questions during the tenth week of the semester to determine each student's level of acceptance of evolution, using a 5-point Likert scale. Kappa's interrater reliability was 0.95 . The raters discussed the slight scoring differences and agreed on consensus ratings, where $69 \%$ of students completely accepted evolution, $16 \%$ mostly accepted evolution, $12 \%$ had neutral/unknown evolution acceptance, $4 \%$ mostly did not accept evolution, and $0 \%$ completely did not accept evolution.

The thematic analysis of the responses to the open-ended questions revealed that $69 \%$ of students mentioned that teleology was a new concept to them during this course. The lack of awareness of teleological reasoning in students' own thinking is shown in representative quotes below. 
"I had never previously heard of teleological statements before this class. It's interesting to change my cognitive process of automatically attributing a purpose to the existence of things."

"My use of the term teleology was non-existent before I took this class[...]teleology was nowhere to be found in my personal lexicon until I encountered the word in this class."

"I have been seeing life in a less teleological way. I was new to the word teleology."

"Before this class I didn't know what teleology was. I think it is a very interesting concept that I definitely accept like most of the things in this class."

"I am now able to look at evolution through a biological perspective which has helped me to really solidify my understanding. I have also begun to attempt to not think teleologically about evolution, which is something I had no concept [of] before this class."

The vast majority of students (84\%) mentioned that, as a result of the course, their use of teleological thinking/awareness has changed or decreased and that they are now more aware of evolutionary mechanisms as causal factors, rather than an end goal, functionality or purpose, as causal factors in evolution. For example,

"My cognizant awareness of how teleology infiltrates thinking about how the world works has increased over the course of this class. It is so easy to fall into teleological reasoning, as if an intelligent designer crafted the material universe. However, I don't believe in such a creator, so it is important for my language to accurately reflect my perspective."

"I find it fascinating how my way of thinking has changed. Instead of just thinking of the purpose of our lives I have become more aware of the causes as well."

The majority of students viewed thinking non-teleologically about human evolution to be a persistent challenge during the semester. $71 \%$ of students mentioned that it is easier for them to think that evolution has a purpose and more difficult to think about evolution as a random, non-directed process.

"It is very easy to think of evolution as having a purpose and direction, so the idea that it is random was the hardest part for me to grasp."

"I still have a difficult time understanding the non-teleological way of thinking in evolution and the ideas of unguided, directionless occurrences."

"At first, thinking teleologically was very hard not to do and it was slightly confusing to refrain from this way of talking and thinking because it felt like the logical, natural way to explain things."

"There always seems to be a way to find exceptions to this non-teleological way of thinking and this was also evident in our class discussions. Natural selection being a completely random process does not make much sense to me since the goal is always to influence reproduction in a positive light. To me, 
evolution seems very purpose driven. If it was completely random and purposeless then isn't there a chance that the least fit individuals might be able to survive some of the time? There is a lot of research and information about teleology that I would love to read about and learn more from, but to be honest I struggle immensely to not see the purpose behind it. I believe that natural selection is a real process, but couldn't it also be a beautifully created process designed to help the fittest individuals adapt and survive? If it is really true that we are here completely by chance, and there was and is no real purpose for our own individual lives, then why does anything we ever do matter? Why would having a moral code matter? It is these questions I had to ask myself when we talked about this topic, and it is for these reasons I believe teleology to be impossible to reject."

"It is still so hard for me to not think teleologically when thinking about evolution. I feel like everything is supposed to have a purpose, but when really its just natural causes, and that we evolved this way by chance. I will say that my use of teleology has changed, but I still continue to use teleological statements because I was just raised to believe that everything happens for a reason."

Over a third of students (37\%) mentioned that they viewed teleological thinking as a potential obstacle to learning/accepting evolution.

"It is very hard to not think of things as having a cause or reason behind them. I'm still slipping and it seems like everyone in this class does as well."

"We have a hard time thinking of things as natural and random, probably because you have to extend your thoughts past the human lifetime, to a more grand overarching idea about life. I definitely understand that nature does not have a purpose, but sometimes it's easy to explain things as if it does have a purpose for simplicity."

"I think it is difficult for humans to avoid attributing purpose to natural occurrences within nature because knowing the cause of everything helps us feel as though we have a better grasp on the way things are. [...]Being in the course has transitioned my use of teleological thinking because I agree that it causes misunderstanding and misconceptions of the occurrence of natural events."

\section{Discussion}

This study provides evidence to support the inclusion of direct challenges to design-based teleological thinking in evolution courses. We combined quantitative and qualitative analyses to determine the effects of addressing students' endorsement of teleological reasoning in an undergraduate evolution course.

\section{Change in student endorsement of teleology (RQ1)}

Via in-class lectures, discussions, quizzes, and out-of-class reflective writing, students decreased their endorsement of design teleological reasoning. The findings of this study support those of others who have shown attenuation of student teleological reasoning in an evolutionary health course $(4,14)$ and an introductory biology course (28). However, the current study used a more comprehensive measure of 
teleological reasoning than the previous studies, which was a 36-item adaptation of the longer assessment by Kelemen et al (7). Cronbach alpha, as a measure of internal consistency of a survey, is notably higher in the current study than the three-question survey used previously by others $(4,14)$. While other studies have utilized a similar strategy of adapting the teleological survey of Kelemen et al $(30,44)$, future research should seek to determine the validity of this survey strategy for assessing student endorsement of teleological reasoning. The significant correlation shown here between the 36-item teleology measure and the six teleology-themed CINS questions provides preliminary evidence of criterion validity for the teleology measure used in this study.

The data presented here support the pedagogical framework of González Galli et al (15) that introducing the concept of teleological thinking and providing repeated opportunities for students to practice challenging their tendency to endorse teleological reasoning attenuates this cognitive bias. However, teleological reasoning did not disappear, even with such rigorous challenges. Although endorsement of teleological reasoning decreased by $33 \%$ (Hedges' $g=1.20$ ), the fact that it persisted is evidence of the durability of this way of thinking. Others have similarly shown persistent teleological reasoning following anti-teleology instruction in an evolutionary course $(4,14,25,27,28)$. Kelemen et al $(7)$ have shown that teleological reasoning persists even in professional physical scientists under speeded conditions. Therefore, our data support the pedagogical stance of González Galli et al (15) to not strictly aim instruction to eliminate teleological reasoning, but instead to shift the teaching focus onto preparing students to regulate their use of teleological reasoning through metacognition. González Galli et al (15) argue that while teleological reasoning should be regulated, there may be some heuristic, explanatory, or predictive value in teleological statements, under appropriate scientific circumstances. Some authors have described legitimate uses of teleology in biology, such as selective (in contrast to design, see (8)) and epistemological (in contrast to ontological, see $(10)$ ) teleology. See $(15,45,46)$ for suggestions on teaching strategies to help students self-regulate their inappropriate use of teleology beyond those pedagogical strategies presented here.

Relationship between teleological reasoning and understanding and acceptance of natural selection (RQ2)

Our data show that student endorsement of teleological reasoning was a significant predictor of student understanding of natural selection prior to the semester. Furthermore, teleological reasoning was correlated with understanding of natural selection at both pre- and post-semester. However, in contrast to the findings of Barnes et al (4), teleological reasoning was not a predictor of post-semester CINS score. We were surprised by this finding given the large effect size in student endorsement of teleological reasoning and the strong correlation between teleological reasoning and CINS score at post-semester. These findings suggest that post-semester understanding of natural selection was likely influenced by several additional factors, including student acceptance and religiosity, and not teleological reasoning alone. Although not significant factors in the multiple regression, student endorsement of teleological reasoning, student religiosity, and acceptance of evolution, were all significantly correlated with CINS score at post-semester. Instead, the strongest predictor of post-semester CINS score was pre-semester 
CINS score. Therefore, our findings indicate that challenges to teleological reasoning remain pedagogically worthwhile since teleological reasoning was the strongest predictor of students' incoming understanding of natural selection. These findings support the suggestion of Evans and Rosengren (47) that investigating one's intuitive teleological reasoning in biology may likely serve as a learning bridge for a deeper understanding of veridical evolutionary mechanisms, especially when metacognitive exercises allow for the identification and subsequent correction of teleological errors.

Student acceptance of evolution was also significantly correlated with understanding of natural selection at both pre- and post-semester. Multiple regression analysis showed that parent attitude towards evolution predicted student acceptance of evolution (and human evolution) more than religiosity or prior educational exposure, indicating that parent attitudes may be more important for student acceptance of evolution than strength of personal religious beliefs and prior education among this population.

\section{Students' metacognitive perceptions of the use of teleological reasoning (RQ3)}

Thematic analysis of student written responses revealed that the concept of thinking teleologically was new to most students prior to this course and that students perceived an increased metacognitive awareness of their own teleological reasoning during the course. Therefore, not only does teleological reasoning have negative consequences on student understanding of natural selection, but students are mostly unaware they possess this cognitive bias prior to explicit teleological intervention, including antiteleological instruction, weekly discussions, and reflection.

The thematic analysis revealed that the concept of teleology was entirely new to $69 \%$ of students, although the actual proportion is likely to be higher since students were not asked directly about their prior awareness of teleology. Importantly, $84 \%$ said they are now more aware of veridical mechanistic causes, rather than design teleology in biology, consistent with our quantitative measure that all, but two students, decreased endorsement of teleological reasoning. Yet, $71 \%$ described persistent difficulties thinking non-teleologically and nearly half mentioned that they view thinking teleologically as a cognitive obstacle to truly understanding evolution. Taken together, the qualitative data reveal that even as late as their Junior year, undergraduates are largely unaware of the concept of teleology and find thinking in nonteleological ways to be challenging, but worthwhile.

Our quantitative and qualitative data together support the importance of addressing design teleology in a human-focused evolution course. Our data confirm that students enter the classroom with high levels of teleological reasoning, which disrupts their understanding of natural selection $(4,6,14,15)$. Nearly all students mentioned that their understanding of evolution deepened and many of these students associated their augmented knowledge and appreciation of evolution with their novel awareness of their own endorsement of teleological reasoning. Several students expressed satisfaction with the metacognitive process of evaluating their own bias about evolution. Therefore, guiding students in exploration of their use of teleological reasoning is a valuable function of the human evolution course. Additionally, the value of addressing teleological misconceptions and enhancing understanding of evolution extends beyond classroom goals, as application of evolution can help students make informed decision as 
educated members of society on topics such environmental and ecological issues as well as healthrelated choices (48).

\section{Limitations}

A chief limitation of this study is related to the absence of a validated measure of teleological reasoning. However, this study used 36-items selected from Kelemen et al (7), which had a very high Cronbach alpha and preliminary evidence for criterion validity in our sample. The demonstration of reliability and criterion validity of this measure in this sample is preliminary support for use of this measure and efforts to further validate this instrument. Another potential limitation identified by Gouvea and Simon (49) is that the wording of teleology questions in a survey may cause students to inappropriately agree with a teleological statement as veridical simply because they might identify a true relationship between the two variables in the question, not necessarily because they think the teleological statement is true. For instance, in a test statement used in this study like "Trees produce oxygen so that animals can breathe," Gouvea and Simon suggest that the student may not believe that oxygen production is caused by the role that trees play, but instead that the student may nonetheless agree with the statement to acknowledge the important role that trees play as oxygen producers (49). However, the use of a Likert scale in our measure may correct for the possibility of inappropriately agreeing with a teleological statement because students would not have to fully accept the statement as they would if they were given only a twoalternative forced-choice option (49). Furthermore, it is possible students may be confused by questions, especially ones that implicitly rather than explicitly present teleology (49). However, insights from the qualitative data in this study allowed us to better understand the students' experiences of learning about design teleology in this course.

There are additional limitations to the data presented here. To protect privacy of students, all data were collected anonymously which prevented the direct linking of quantitative data with qualitative responses or final course grades. Therefore, we were unable to determine if certain themes in student writing were related to the quantitative measures of understanding natural selection, acceptance of evolution, or teleological reasoning. Lastly, this study had a limited sample size and may lack generalizability to the wider population. Students who oppose human evolution are doubtful to elect a class on evolutionary medicine, which may cause selection bias and skew data toward acceptance and decreased teleological thinking compared with a representative sample. However, there were no differences prior to the semester between the teleology intervention and control groups on any measure.

Lastly, Long (50) suggested that students are aware of the expectations placed on them by the teacher to increase their understanding and acceptance of evolution in an evolution course which may influence their responses to both the survey and open-ended questions. While the anonymity of the responses likely reduced this impact, there is a possibility that students were attempting to present what they think the professor wanted to hear and not what they actually think.

\section{Conclusion}


Design teleological reasoning was a new concept for the vast majority of upper level undergraduates in an evolution course, but explicit and direct challenges to design teleological thinking attenuated student teleological reasoning in a human evolution course. The concept of teleological reasoning should be defined for students and introduced with numerous examples of how it can be expressed and how it's inappropriate use can disrupt student understanding of veridical evolutionary mechanisms. Furthermore, students should be given repeated opportunities to practice regulation of their teleological reasoning through classroom discussion and reflective writing.

\section{Declarations}

\section{Availability of Data and Materials}

The datasets supporting the conclusions of this article are available in the Open Science Framework repository, https://osf.io/4cq3e/?view_only=252d3ee79e944ad48797f00a3a48131b.

\section{Funding and Conflicts of Interest}

There was no funding for this project and the authors have no conflicts of interest.

\section{Author's contributions}

Jason Wingert Conception and design of study, statistical analysis, data interpretation, manuscript authorship

Gennie Bassett Manuscript authorship

Caitlin Terry Data analysis and interpretation

Jimin Lee Statistical analysis, data interpretation, manuscript authorship

\section{Acknowledgements}

Not applicable

\section{References}

1. Gregory TR. Understanding Natural Selection: Essential Concepts and Common Misconceptions. Evolution: Education and Outreach. 2009 Jun;2(2):156.

2. Smith MU. Current Status of Research in Teaching and Learning Evolution: II. Pedagogical Issues. Sci \& Educ. 2010 Jun 1;19(6):539-71.

3. Dunk RDP, Petto AJ, Wiles JR, Campbell BC. A multifactorial analysis of acceptance of evolution. Evolution: Education and Outreach. 2017 Jul 17;10(1):4. 
4. Barnes ME, Evans EM, Hazel A, Brownell SE, Nesse RM. Teleological reasoning, not acceptance of evolution, impacts students' ability to learn natural selection. Evolution: Education and Outreach. 2017 Oct 2;10(1):7.

5. Kelemen D. Teleological minds: How natural intuitions about agency and purpose influence learning about evolution. In: Rosengren K, Brem S, Evans EM, Sinatra G, editors. Evolution challenges: Integrating research and practice in teaching and learning about evolution. Oxford: Oxford University Press; 2012.

6. Hammann M, Nehm RH. Teleology and evolution education: introduction to the special issue. Evolution: Education and Outreach. 2020 Jul 7;13(1):16.

7. Kelemen D, Rottman J, Seston R. Professional physical scientists display tenacious teleological tendencies: purpose-based reasoning as a cognitive default. J Exp Psychol Gen. 2013 Nov;142(4):1074-83.

8. Kampourakis K. Students' "teleological misconceptions" in evolution education: why the underlying design stance, not teleology per se, is the problem. Evolution: Education and Outreach. 2020 Jan 9;13(1):1.

9. Moore R, Mitchell G, Bally R, Inglis M, Day J, Jacobs D. Undergraduates' understanding of evolution: ascriptions of agency as a problem for student learning. Journal of Biological Education. $2002 \mathrm{Mar}$ 1;36(2):65-71.

10. Trommler F, Hammann M. The relationship between biological function and teleology: Implications for biology education. Evolution: Education and Outreach. 2020 May 29;13(1):11.

11. Bishop B, Anderson C. Student conceptions of natural selection and its role in evolution. Journal of Research in Science Teaching. 1990;27(5):415-27.

12. Demastes SS, Good RG, Peebles P. Patterns of conceptual change in evolution. Journal of Research in Science Teaching. 1996;33(4):407-31.

13. Settlage J. Conceptions of Natural Selection: A Snapshot of the Sense-Making Process. Journal of Research in Science Teaching. 1994;31(5):449-57.

14. Wingert JR, Hale RE. Teaching Evolutionary Principles in Health Promotion: A Pilot Study. Pedagogy in Health Promotion. 2021 Mar 1;7(1):60-70.

15. González Galli L, Peréz G, Gómez Galindo AA. The self-regulation of teleological thinking in natural selection learning. Evolution: Education and Outreach. 2020 Apr 30;13(1):6.

16. Werth A, Allchin D. Teleology's long shadow. Evolution: Education and Outreach. 2020 Mar 5;13(1):4.

17. Kelemen D. The scope of teleological thinking in preschool children. Cognition. 1999 Apr 1;70(3):241-72.

18. Kelemen D. Function, goals and intention: children's teleological reasoning about objects. Trends in Cognitive Sciences. 1999 Dec 1;3(12):461-8.

19. Kelemen D, DiYanni C. Intuitions About Origins: Purpose and Intelligent Design in Children's Reasoning About Nature. Journal of Cognition and Development. 2005 Feb 1;6(1):3-31. 
20. Kelemen D. British and American children's preferences for teleo-functional explanations of the natural world. Cognition. 2003 Jun 1;88(2):201-21.

21. Jungwirth E. Do Students Accept Anthropomorphic and Teleological Formulations as Scientific Explanations? Journal of College Science Teaching. 1979 Jan;8(3):152-5.

22. Richardson DR. A Survey of Students' Notions of Body Function as Teleologic or Mechanistic. Advances in Physiology Education. 1990;3(1).

23. Southerland SA, Abrams E, Cummins CL, Anzelmo J. Understanding students' explanations of biological phenomena: Conceptual frameworks or p-prims? Science Education. 2001;85(4):328-48.

24. Kampourakis K, Zogza V. Preliminary Evolutionary Explanations: A Basic Framework for Conceptual Change and Explanatory Coherence in Evolution. Sci \& Educ. 2009 Oct 1;18(10):1313-40.

25. Pedersen S, Halldén O. Intuitive ideas and scientific explanations as parts of students' developing understanding of biology: The case of evolution. Eur J Psychol Educ. 1994 Jun 1;9(2):127.

26. Kelemen D, Rosset E. The Human Function Compunction: Teleological explanation in adults. Cognition. 2009 Apr 1;111(1):138-43.

27. Stover SK, Mabry ML. Influences of Teleological and Lamarckian Thinking on Student Understanding of Natural Selection. Bioscene: Journal of College Biology Teaching. 2007 Mar;33(1):11-8.

28. Jensen MS, Finley FN. Teaching Evolution Using Historical Arguments in a Conceptual Change Strategy. Science Education. 1995;79(2):147-66.

29. Brumby MN. Misconceptions about the concept of natural selection by medical biology students. Science Education. 1984;68(4):493-503.

30. Roberts AJ, Wastell CA, Polito V. Teleology and the intentions of supernatural agents. Consciousness and Cognition. 2020 Apr 1;80:102905.

31. Schachner A, Zhu L, Jing L, Kelemen D. Is the bias for function-based explanations culturally univeral? Children from CHina endorse teleological explanations of natural phenomena. Journal of Experimental Child Psychology. 2017;157:29-48.

32. Järnefelt E, Canfield CF, Kelemen D. The divided mind of a disbeliever: Intuitive beliefs about nature as purposefully created among different groups of non-religious adults. Cognition. $2015 \mathrm{Jul} ; 140: 72-$ 88.

33. Bartov H. Can students be taught to distinguish between teleological and causal explanations? Journal of Research in Science Teaching. 1978;15(6):567-72.

34. Bartov H. Teaching Students to Understand the Advantages and Disadvantages of Teleological and Anthropomorphic Statements in Biology. Journal of Research in Science Teaching. 1981 Jan;18(1):79-86.

35. Gresch $\mathrm{H}$, Martens $\mathrm{M}$. Teleology as a tacit dimension of teaching and learning evolution: $\mathrm{A}$ sociological approach to classroom interaction in science education. Journal of Research in Science Teaching. 2019;56(3):243-69. 
36. Jungwirth E. The problem of teleology in biology as a problem of biology-teacher education. Journal of Biological Education. 1975 Dec 1;9(6):243-6.

37. Tamir P, Zohar A. Anthropomorphism and teleology in reasoning about biological phenomena. Science Education. 1991 Jan 1;75(1):57-67.

38. Zohar A, Ginossar S. Lifting the taboo regarding teleology and anthropomorphism in biology education-Heretical suggestions. Science Education. 1998;82(6):679-97.

39. Nadelson LS, Southerland S. A More Fine-Grained Measure of Students' Acceptance of Evolution: Development of the Inventory of Student Evolution Acceptance-I-SEA. International Journal of Science Education. 2012 Jul 1;34(11):1637-66.

40. Anderson DL, Fisher KM, Norman GJ. Development and Evaluation of the Conceptual Inventory of Natural Selection. Journal of Research in Science Teaching. 2002;39(10):952-78.

41. Creswell JW, Clark VLP. Designing and Conducting Mixed Methods Research. SAGE Publications; 2017. $521 \mathrm{p}$.

42. Nehm RH, Schonfeld IS. Measuring Knowledge of Natural Selection: A Comparison of the CINS, an Open-Response Instrument, and an Oral Interview. Journal of Research in Science Teaching. 2008 Dec;45(10):1131-60.

43. Nadelson LS, Hardy KK. Trust in science and scientists and the acceptance of evolution. Evolution: Education and Outreach. 2015 Jun 16;8(1):9.

44. Banerjee K, Bloom P. Why did this happen to me? Religious believers' and non-believers' teleological reasoning about life events. Cognition. 2014 Oct 1;133(1):277-303.

45. Galli LMG, Meinardi EN. The Role of Teleological Thinking in Learning the Darwinian Model of Evolution. Evo Edu Outreach. 2011 Mar;4(1):145-52.

46. Kampourakis K. Conceptual obstacles to accepting evolution. In: Understanding Evolution. Cambridge, UK: Cambridge University Press; 2020. p. 42-62.

47. Evans EM, Rosengren KS. Cognitive Biases or Cognitive Bridges?: Intuitive Reasoning in Biology. In: Teaching Biology in Schools. Routledge; 2018.

48. Barnes ME, Brownell SE. Practices and Perspectives of College Instructors on Addressing Religious Beliefs When Teaching Evolution. LSE. 2016 Jun 1;15(2):ar18.

49. Gouvea JS, Simon MR. Challenging Cognitive Construals: A Dynamic Alternative to Stable Misconceptions. LSE. 2018 Jun 1;17(2):ar34.

50. Long DE. The politics of teaching evolution, science education standards, and Being a creationist. Journal of Research in Science Teaching. 2012;49(1):122-39.

\section{Tables}

Table 1. Spearman correlations among pre-semester variables, assessed prior to presentation of course material 


$\begin{array}{lllll}\begin{array}{l}\text { Parental } \\ \text { attitude }\end{array} & \begin{array}{l}\text { Student } \\ \text { Religiosity }\end{array} & \begin{array}{l}\text { Evolution } \\ \text { acceptance }\end{array} & \begin{array}{l}\text { Prior } \\ \text { education }\end{array} & \begin{array}{l}\text { Teleological } \\ \text { (I-SEA) }\end{array} \\ \end{array}$

\begin{tabular}{lll} 
Parental attitude & & \\
Student Religiosity & -0.32 & - \\
\hline & $0.58^{\ddagger}$ & $-0.34^{*}$
\end{tabular}

Evolution acceptance (ISEA)

$\begin{array}{llll}\text { Prior education } & 0.28 & -0.07 & 0.36^{*}\end{array}$

Teleological reasoning

$0.35^{*} \quad-0.44^{+}$

$-0.19$

$-0.25$

Natural Selection

Understanding (CINS)

$0.15-0.30^{*} \quad 0.30^{*}$

${ }^{*} p<0.05 ;{ }^{\dagger} p £ 0.01 ;{ }^{\ddagger} p £ 0.001$

Table 2. Spearman correlations among post-semester variables, assessed after presentation of course material 


$\begin{array}{lllll}\begin{array}{l}\text { Parental } \\ \text { attitude }\end{array} & \begin{array}{l}\text { Student } \\ \text { Religiosity }\end{array} & \begin{array}{l}\text { Evolution } \\ \text { acceptance } \\ \text { (I-SEA) }\end{array} & \begin{array}{l}\text { Prior } \\ \text { education }\end{array} & \begin{array}{l}\text { Teleological } \\ \text { reasoning }\end{array} \\ & & & \end{array}$

\section{Parental attitude}

$$
-0.35^{*}
$$

Student religiosity
$0.49^{\ddagger}$
$-0.50^{\ddagger}$

Evolution acceptance (I-

SEA)
0.28
$-0.03$
$0.41^{\dagger}$

Prior education

Teleological reasoning

0.20

$-0.51^{\ddagger}$

$-0.36^{*}$

$-0.37^{\star}$

Natural Selection

Understanding (CINS)

$\begin{array}{lll}0.28 & -0.39^{\dagger} & 0.39^{\dagger}\end{array}$

$-0.38^{\dagger}$

0.18

${ }^{*} p<0.05 ;{ }^{\dagger} p £ 0.01 ;{ }^{\ddagger} p £ 0.001$

Table 3. Results from a multiple linear regression of pre-semester student evolution acceptance (I-SEA).

\begin{tabular}{lll} 
& B & SE B \\
\hline Intercept & 90.26 & 16.44 \\
\hline Parental attitude-evolution & $5.62^{\dagger}$ & 1.60 \\
\hline Student religiosity & -1.58 & 1.60 \\
\hline Prior educational exposure & 2.03 & 1.53 \\
\hline Teleological reasoning & -4.24 & 2.96 \\
\hline CINS $_{\text {pre }}$ & 0.12 & 0.80 \\
\hline Adjusted R & 0.38 &
\end{tabular}

${ }^{*} p<0.05 ;{ }^{\dagger} p £ 0.01 ;{ }^{\ddagger} p £ 0.001$

Table 4. Results from a multiple linear regression of student pre-semester understanding of natural selection (CINS). 


\begin{tabular}{|lll|}
\hline & B & SE B \\
\hline Intercept & 15.10 & 3.45 \\
\hline Parental attitude-evolution & -0.004 & 0.35 \\
\hline Student religiosity & -0.16 & 0.31 \\
\hline ISEA-HE $_{\text {pre }}$ & 0.004 & 0.031 \\
\hline Prior educational exposure & 0.11 & 0.30 \\
\hline Teleological reasoning pre & $-2.18^{\dagger}$ & 0.481 \\
\hline Adjusted $\mathrm{R}^{2}$ & 0.35 & \\
\hline
\end{tabular}

${ }^{\dagger} p £ 0.001$

Table 5. Results from a multiple linear regression of student post-semester understanding of natural selection (CINS).

\begin{tabular}{|lcl|}
\hline & $\mathrm{B}$ & $\mathrm{SE} \mathrm{B}$ \\
\hline Intercept & 3.34 & 3.59 \\
\hline Parental attitude-evolution & 0.23 & 0.24 \\
\hline Student religiosity & -0.36 & 0.25 \\
\hline ISEA-HE & & \\
post & 0.013 & 0.026 \\
\hline Prior educational exposure & 0.081 & 0.23 \\
\hline Teleological reasoning & 0.35 & 0.41 \\
\hline CINS- ${ }_{\text {pre }}$ & $0.51^{\ddagger}$ & 0.11 \\
\hline Adjusted $\mathrm{R}^{2}$ & 0.45 & \\
\hline
\end{tabular}

${ }^{\ddagger} p £ 0.001$

Figures 
Figure 1. Box and whisker plots of (A) student endorsement of teleological reasoning, (B) understanding of natural selection (CINS without six teleological questions), (C) acceptance of evolution (ISEA), and (D) acceptance of human evolution (ISEA-HE), at pre- and post-semester for the evolution course with teleological intervention (TI, gray) and control courses (white). Pvalues and means $(+)$ are shown.
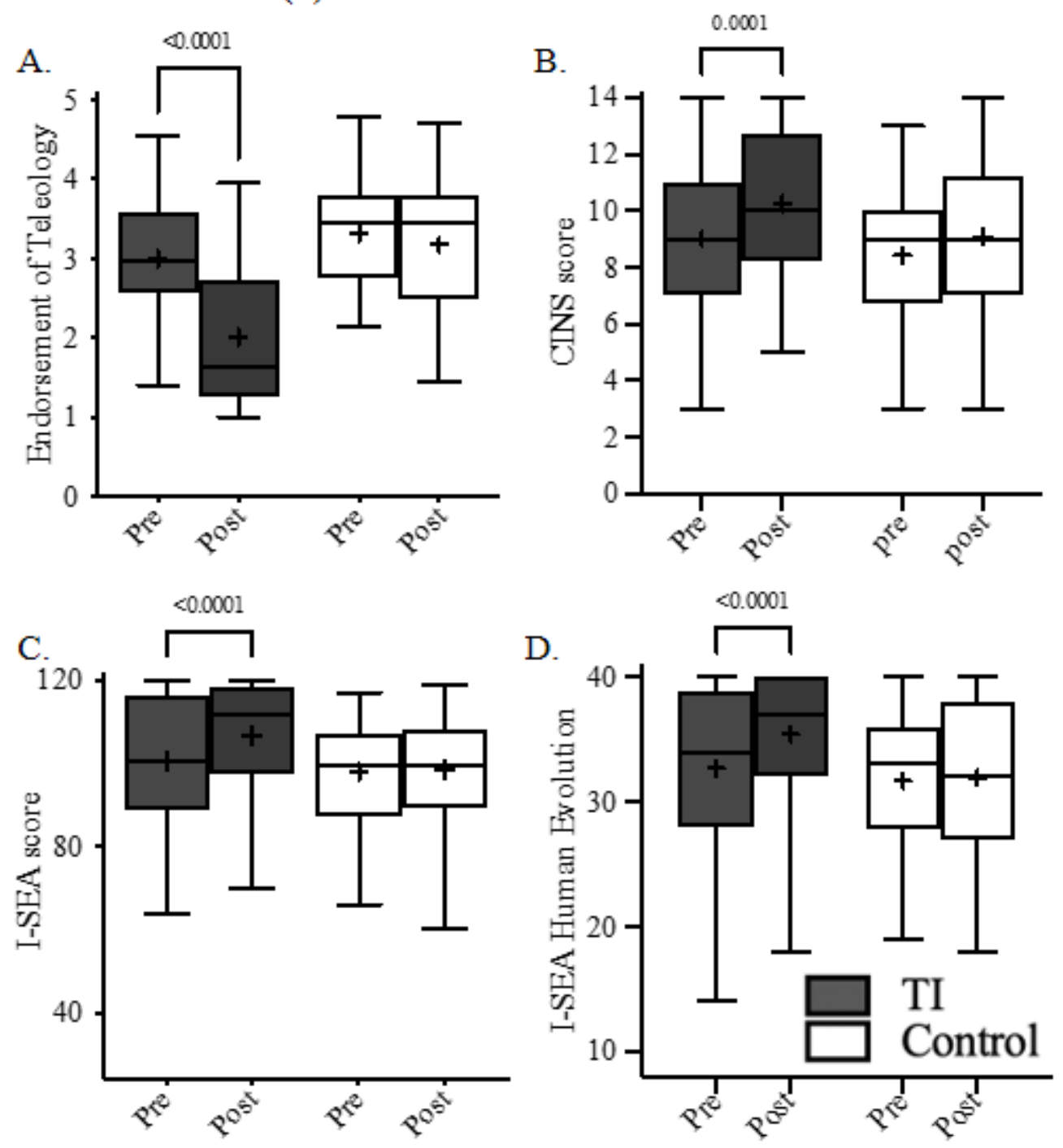

Figure 1

See image above for figure legend.

\section{Supplementary Files}

This is a list of supplementary files associated with this preprint. Click to download.

- Additionalfile1.docx

- Additionalfile2.docx

- Additionalfile3.docx 